\title{
Anatomy Curriculum: Perception of Indian Undergraduate Medical Students
}

\author{
Rokade, S.A. ${ }^{1}$ \& Shinde, R.B. ${ }^{2}$
}

\begin{abstract}
Introduction: Anatomy curriculum for undergraduate medical students in India is squeezed from one and half year to one year since 1998 as per Medical Council of India (MCI) regulation, 1997 leading to pressure of completing the vast syllabus in this time frame. Further $\mathrm{MCl}$ recommends student centered teaching in the form small group teaching, seminars, formative assessments etc. The present study was conducted to determine the students' perception about these changes.
\end{abstract}

Method: A total of 360 students participated in the study during two academic years. Students' feedback was collected through pre-structured objective questionnaire at the end of each academic year and the responses were analyzed statistically.

Result: About two-third (65\%) students expressed that duration provided to study anatomy in the current curriculum is insufficient and should be increased to 10-12 months. Reasons cited were more time required for acclimatization, syllabus being rushed through, significant stress level and insufficient time for recreation. About $76.38 \%$ students suggested that number of teaching hours per day should be reduced to 5-6 hours from current 7 hours. Students gave less than $50 \%$ weightage to college coaching $(87.77 \%)$, opted for small group teaching $(79.44 \%)$ and preferred appropriate combination of teaching with chalk-board \& power point presentation (55.83\%). They favoured formative tests and revisions in learning anatomy than seminars.

Conclusion: The present study provides useful insights of student's perception on current anatomy curriculum and teaching. Findings warrant confirmation by similar studies in different medical colleges. These data will enable betterment of curriculum during its revisions.

Keywords: Anatomy, Curriculum, Students' Perception.

\section{Introduction}

It is very well accepted in the scientific and clinical community that knowledge of Anatomy is very important for subsequent understanding of clinical subjects and practice as well (Hanna SJ \& Freeston, 2002; Mc Cuskey et al., 2005; Gole et al., 2015). Anatomy curriculum for undergraduate medical students in India used to be conducted over one and half year till the year 1997.

\footnotetext{
${ }^{1}$ Associate Professor, Department of Anatomy, B J Government Medical College, Pune, India.

${ }^{2}$ Assistant Professor, Department of Anatomy, B J Government Medical College, Pune, India.

Corresponding Author:

Dr. Reshma B Shinde,

Department of Anatomy, B J Government Medical College, Pune, India.

Email: sreshma10@gmail.com
}

Since 1998 till academic year 2018-19, Anatomy curriculum is conducted over one year as per Medical Council of India (MCI) regulation, 1997, (Medical Council of India, 1997). Considering vacations, holidays and period allocated for examinations, actual teaching days are 240. Currently, in our medical college, coaching for 1st MBBS is done from $9.00 \mathrm{am}$ to $5.00 \mathrm{pm}$ i.e. total 7 hours a day. Of the total number of teaching hours available in an academic year, approximately $2 / 3 r d$ is allocated to teach anatomy subject. The faculty is burdened to complete the vast syllabus of Anatomy within a short duration. While communicating with the students informally, we came to know that the students are equally stressed and affected. There are many aspects to this issue. However data addressing this is meager (Nagar et al., 2012; Jaiswal et al., 2015).

DOI: http://doi.org/10.4038/seajme.v13i2.212

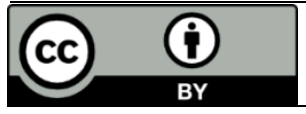

62

(C) SEAJME. This is an Open Access article distributed under the terms of the Creative Commons Attribution License (http://creativecommons.org/licenses/by/4.0/), which permits unrestricted use, distribution, and reproduction in any medium, provided the original author and source are credited 
$\mathrm{MCl}$ promotes small group teaching. It also recommends more participation of students in seminars and group discussion (Medical Council of India, 1997). To have better learning, we give revisions at the end of teaching for each region. Now-a-days, the use of modern audio-visual aids is increased in teaching (Fischer et al., 2004; Jaiswal et al., 2015). Though students centered teaching is now promoted, there is no data on how students perceive these changes. It is imperative to generate these data for betterment of planning and revisions of curriculum.

With this background, the present study was undertaken to understand the perception of $1 \mathrm{st}$ MBBS students about the current duration allocated for anatomy curriculum, small group teaching and the modern audio-visual aids used in teaching. We also studied their opinion about usefulness of seminars, revisions \& formative assessment tests in learning Anatomy.

\section{Methods}

The study was conducted in Department of Anatomy, B J Government Medical College, Pune during academic years 2017-18 \& 201819. The study design was approved by Institutional Ethical Committee. The 1st MBBS students were explained the study and appealed to participate in it. A total of 360 students participated in the study voluntarily (181 students in the academic year 2017-18 and 179 students in the academic year 201819). Informed written consent was taken from each participant.

An objective structured questionnaire was designed which included a total of 18 items (11 questions \& 7 statements). These included items seeking opinion of students regarding the approximate time required for initial acclimatization, whether the current period allotted to learn anatomy was sufficient, whether the syllabus was taught hurriedly, whether the students were under stress while perceiving the course of anatomy, whether they could give sufficient time for extracurricular activities, weightage given to college coaching and self-study, whether they needed extra coaching. Opinions were also sought on their preference for chalk-board teaching versus Power Point Presentations and small group teaching versus large group teaching. The students were further asked to grade the usefulness of seminars, revisions and formative assessment tests in learning anatomy.
The responses to the statements were sought on 5 - point Likert's scale. The participants were given the questionnaire at the end of each of the academic years mentioned previously. They were appealed to give their frank \& honest opinion. Further to evoke frank response, anonymity was maintained. The responses were analyzed statistically. Fisher's exact test was applied.

\section{Results}

All the students returned the questionnaire and responded to all questions and statements, resulting in $100 \%$ response rate.

1. Time required for initial acclimatization to anatomy subject:

Of the 360 student responses it was observed that $59.99 \%$ of the students took $1-2$ months to acclimatize the course, while $34.16 \%$ of them took more than 3 months. The commonest reason cited for delayed acclimatization was newer terminologies in anatomy $(70.27 \%$ students), followed by new atmosphere (16.66\% students).

\section{Duration of course:}

About two-third (65\%) students responded that the current period given to study anatomy i.e. 8 months ( 240 days) is insufficient. A total of 41.4 $\%$ students opined that approximate duration required to study anatomy is 12 months ( 360 days), while $25 \%$ of them expressed that it should at least be 10 months (300 days).

\section{Number of teaching hours per day:}

The students revealed that they face average to above average stress in current scenario $(71.38 \%)$. About half the students $(54.16 \%)$ felt that the classes should be conducted for 5 hours per day instead of current 7 hours, while $22.22 \%$ of students felt that the classes should be taken for 6 hours per day. When asked about ideal time for lecture, $83.61 \%$ of the students favored timing of $9.00 \mathrm{am}$ to $11.00 \mathrm{am}$, while $14.44 \%$ favored lectures during $11.00 \mathrm{am}$ $1.00 \mathrm{pm}$.

4. Time management during teaching the syllabus:

The students' opinions about time management during teaching anatomy syllabus and stress they faced during 1 st MBBS is depicted in Table 1. 
Table 1: Students feedback about Time management during teaching anatomy

\begin{tabular}{lcccc}
\hline \multicolumn{1}{c}{ Statement } & $\begin{array}{c}\text { Disagree } \\
(\%)\end{array}$ & Neutral (\%) & Agree (\%) & P value \\
\hline $\begin{array}{l}\text { Syllabus was rushed \& completed } \\
\text { hurriedly }\end{array}$ & $67(18.61)$ & $51(16.94)$ & $233(64.72)$ & $<0.0001^{*}$ \\
$\begin{array}{l}\text { I need extra coaching in Anatomy } \\
\text { n was under significant amount of stress }\end{array}$ & $28(7.77)$ & $188(32.77)$ & $208(57.77)$ & $<0.0001^{*}$ \\
$\begin{array}{l}\text { during the anatomy course } \\
\begin{array}{l}\text { I was able to give proper weightage to } \\
\text { extracurricular activities }\end{array}\end{array}$ & $206(57.22)$ & $50(13.88)$ & $104(28.88)$ & $<0.0001^{*}$ \\
\hline${ }^{*}$ Extremely Statistically Significant & & & $165(45.83)$ & 0.1075 \\
\hline
\end{tabular}

The comparative data of weightage given by the students to college coaching and self-study is given in Figure 1. Figure 2 depicts proportion of students preferring small group teaching and large group teaching. Percentage of students preferring chalk-board teaching over power- point presentation is depicted in Figure 3, while students' perception about usefulness of seminars, revisions and formative assessment tests in learning anatomy is shown in Figure 4.

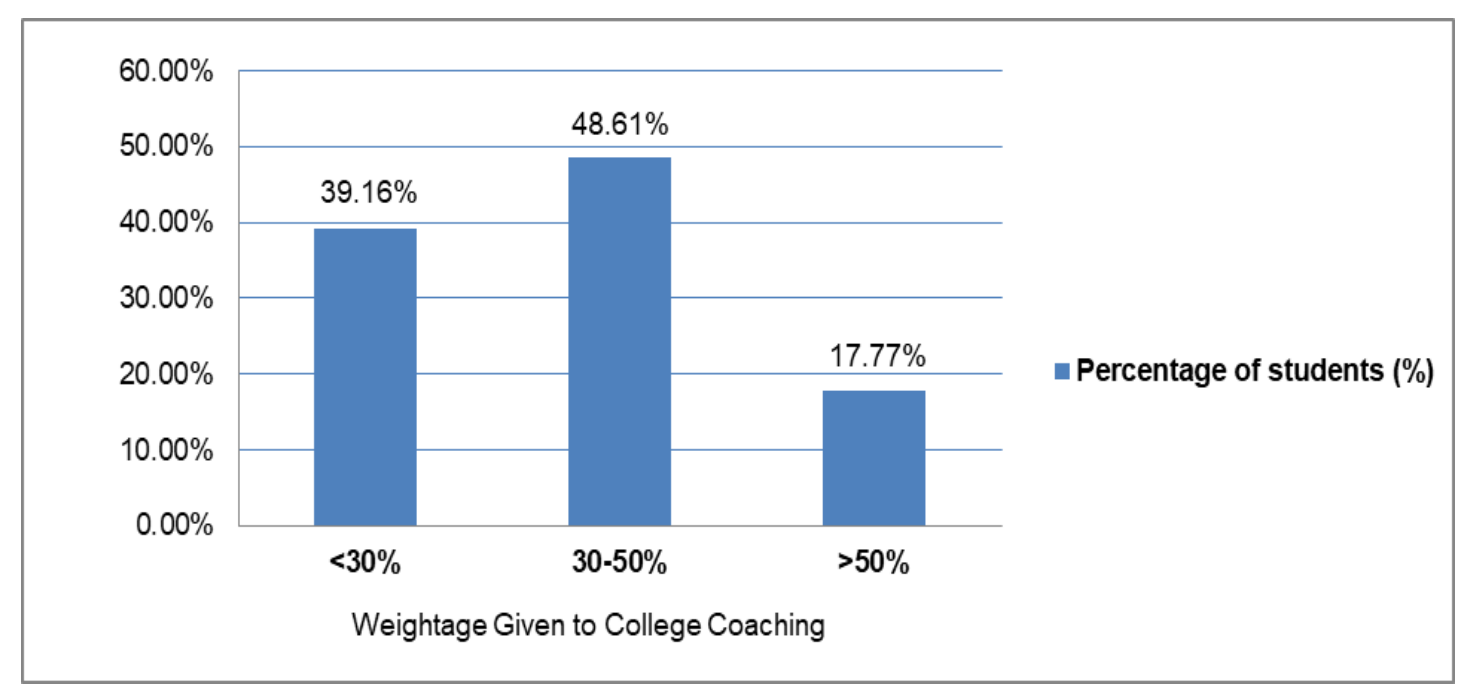

Figure 1: Percentage of weightage given by the students to college coaching during studying Anatomy 


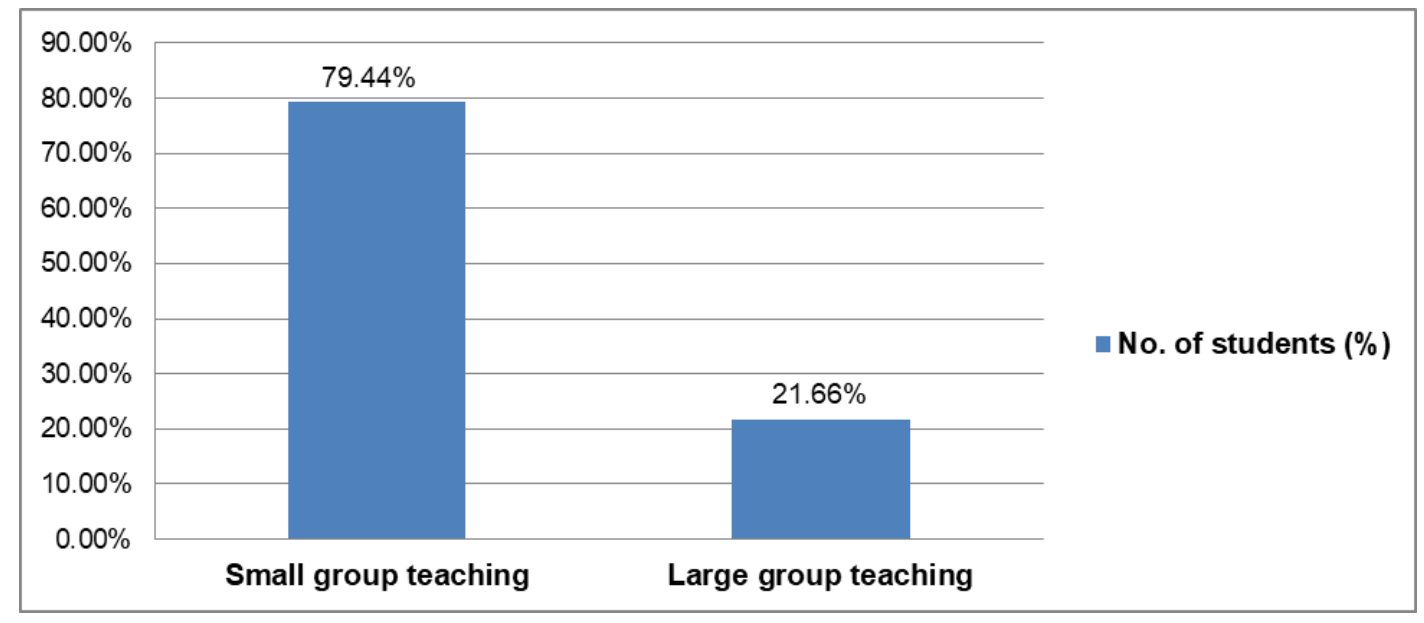

Figure 2: Proportion of students preferring small group teaching over large group teaching

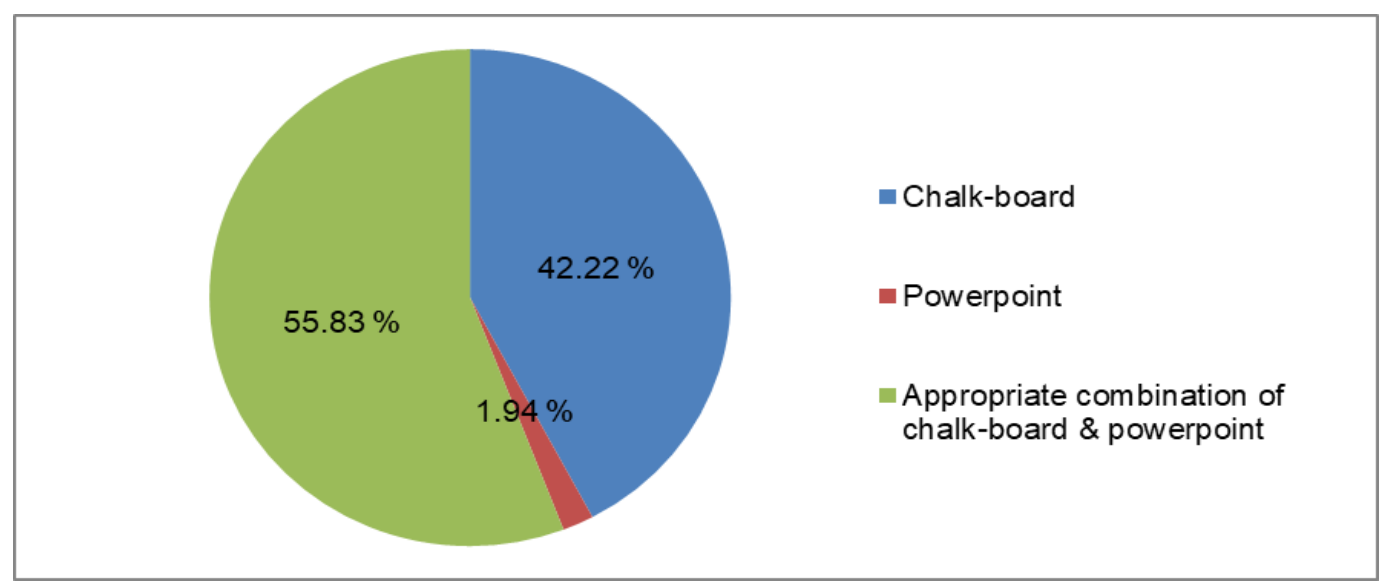

Figure 3: Proportion of students preferring Chalk-board teaching over Power-point presentation

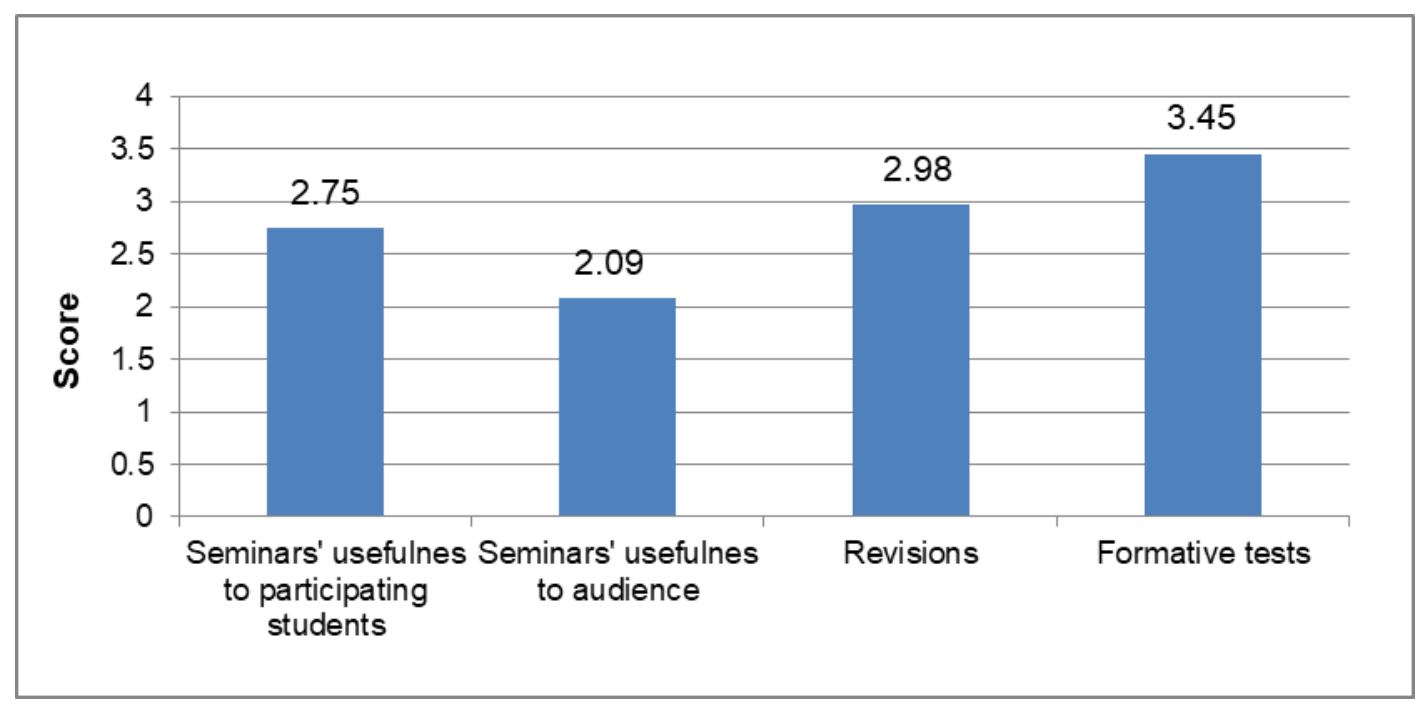

Figure 4: Students perception about usefulness of Seminars, Revisions, and Formative assessment tests in learning anatomy 


\section{Discussion}

Over previous two decades, the course of anatomy has been squeezed from medical curriculum. Previously it was conducted over one and half years. However, the $\mathrm{MCl}$ reduced it to one year (Medical Council of India, 1997). Considering the period allocated to vacations, holidays and examinations, the Anatomy departments used to get only eight months to teach Anatomy syllabus. This results in a lot of stress not only to teachers but to the students as well. There are many aspects to this issue. It is well accepted in scientific and clinical community that knowledge of anatomy has been very important for subsequent understanding of clinical subjects and practice as well (Hanna SJ \& Freeston, 2002; Mc Cuskey et al., 2005; Gole et al., 2015). Studies suggest that the knowledge of the qualifying doctor is now below an acceptable level (McKeown et al., 2003; Prince et al., 2005). Furthermore, researchers have brought out the decline in undergraduate knowledge of anatomy amongst the surgical community (Heylings, 2002; Older, 2004; Sritharan, 2005). Hence it is important to gather data for planning medical curriculum.

As we promote the student centered teaching, the students' views about the curriculum and teaching-learning methods should be taken into account to identify areas of strength and/or weakness in the curriculum and teaching/learning methods used, so that steps can be taken to rectify deficiencies and to evolve the curriculum and achieve intended goal.

Anatomy is a vast and complex subject. It has many new terminologies which the newly admitted students are not familiar with. Also the students are new to the place, college, its culture \& environment, accommodation (hostel) \& food, etc. This leads to difficulty in acclimatization to the course. The same is reflected in the present study. Of the total 8 months of anatomy teaching, our students took 1-3 months to acclimatize to the course.

In our study, overall $86.41 \%$ of the students felt that it is difficult for them to learn anatomy within present 8 months duration. About three-fourth of the students opined that they require 10-12 months to study the subject properly. Similar observation is made by Gole et al., 2015, who reported that $97-100 \%$ of the students felt that the current time frame is inadequate to learn anatomy. Similarly, studies by Nagar et al.,
2012, and Jaiswal et al., 2015 revealed that a significant group of their students were in favor of one and half year course for Anatomy. Displaying notes for topics that are not covered in the classes on notice-boards or distributing them among students may be one of the options to cover the vast syllabus. However this has a drawback that students may face difficulty in understanding the concepts. Horizontal and vertical teaching is suggested as an alternative to tackle this reduced teaching duration (Bandyopadhyay, 2017; Samar, 2010).

This may be due to higher difficulty level of the anatomy subject, as noted by Gole et al., 2015. Two third of the students expressed that the syllabus was rushed through and completed hurriedly. This may be due to less time available for teaching. Obviously, all these factors have created significant stress to the students. Participation in extracurricular activities is not only important for personality development but also acts as a stress buster. However, due to tight college schedule students could not give proper weightage to such activities (Table 1).

Another obvious disadvantage of completing syllabus hurriedly is that students cannot comprehend the subject satisfactorily. In our study, a significant proportion of students expressed that they need extra coaching in Anatomy (Table 1). Also, in this scenario, the students have to rely more on self-study. From figure 1 , it is clearly seen that self-study played important role in learning anatomy for our students.

Students in small group teaching perform better than those exposed to didactic lectures (Dunnington et al., 1987). As per MCl, "lectures alone are generally not adequate as a method of teaching \& are poor means of transferring/acquiring information and even less effective at skill development and in generating the appropriate attitude". Hence, it further recommends that, "every effort should be made to encourage use of active methods related to demonstration. Small group teaching should be encouraged such as to give maximal experience" (Medical Council of India, 1997). Accordingly, we have included small group teaching in our curriculum. In our study, approximately $80 \%$ of the students favored small group teaching over didactic lectures, in agreement with the study by Gole et al., 2015, where $0-6 \%$ students preferred didactic lecture as a teaching aid. When we asked about number of students that should be present in 
the small group, $58.32 \%$ students opined that there should be $10-20$ students in a teaching group, while another one- third students expressed that they are comfortable with 20-25 students. $\mathrm{MCl}$ recommends not more than 20 students in a group for small group teaching. Thus the concept of the small group teaching is well accepted by our students. Our findings are in concordance with Fischer et al., 2004 \& Jaiswal et al., 2015.

Traditionally, anatomy was taught using chalkboard. Now-a-days, the use of advanced teaching aids is increasing. We have started the use of power-point- presentation in our department. About half of the students in our study preferred chalk-board teaching while remaining half preferred appropriate combination of chalk-board \& power-pointpresentation. Our finding is in line with Rokade \& Bahetee, 2013; Jaiswal et al., 2015; Kumari et al., 2015; Petimani et al., 2015 and Chakrabarti et al., 2017. In a study by Bamne \& Bamne, 2016, it was seen that $87 \%$ of the students preferred chalk and board teaching.

According to $\mathrm{MCl}$ regulation, every attempt is to be made to encourage students to participate in group discussion \& seminars to enable them to develop personality, character, expression \& other faculties which are necessary for a medical graduate"(Medical Council of India, 1997). Also as per syllabus designed by our state medical university, we conduct formative assessment tests. We also give revisions to the students at the end of the teaching of each region. From figure 4 , it is clear that from students point of view, formative assessment tests are more useful for learning anatomy than revisions $(p=0.01)$. Similar finding has been recorded by Nagar et al, 2012 who observed that $70.80 \%$ students in their study were in favour of weekly tests. lan et al, 2012 have revealed that formative assessment has an important role in self-regulated learning. Another study by Jaiswal et al., 2015 noted that the best assessment technique to measure knowledge in theory is part completion test. The present study showed that frequent revisions can act as a good learning tool. Our study supports the finding of Chakrabarti et al., 2017.

In our study, students revealed that those students participating in seminars are more benefited from it than the audience $(p<0.0001)$. We also observed that, from students point of view, the revisions and formative assessment tests are far better learning tools than seminars $(p<0.0001)$. However the role of participants in seminar in personality development cannot be ruled out.

Our study had limitation. It was conducted in one medical college in India. To have more realistic picture, similar studies should be conducted at other centres, so that appropriate recommendations can be made to the governing bodies/councils.

\section{Conclusion}

Present study is an attempt to bring out perception of undergraduate medical students about anatomy curriculum. The students felt that the time allotted in current curriculum to study anatomy i.e. 8 months is insufficient and it should be increased to $10-12$ months. The students preferred small group teaching over large group teaching (didactic lectures) and favored an appropriate combination of chalkboard and power point presentation for teaching Anatomy. Formative assessment tests and revisions are deemed useful learning tools by students.

\section{Acknowledgement}

The authors thanks and acknowledge the enthusiastic participation of the students in the study.

\section{Conflict of Interest}

The authors declare no conflict of interest.

\section{References}

Hanna, S.J. \& Freeston, J.E. (2002) Importance of anatomy and dissection: The junior doctors viewpoint. Clinical Anatomy, 15, pp. 377-378.

McCuskey, R.S., Carmichael, S.W. \& Kirch, DG. (2005) The importance of anatomy in Health Professions Education and the shortage of Qualified Educators. Academic Medicine, 80, 4, pp. 349-351.

Gole, R.A., Meshram, P. \& Hattangadi, S. (2015) Changes in perception about anatomy subject after 1st year of medical course. Indian Journal of Basic and Applied Medical Research, 4, 4, pp. 453-457.

Medical Council of India. (1997) Regulations on graduate medical education, 1997. http://www.mciindia.org/CMS/rulesregulations/graduate-medical-educationregulations-1997. Accessed on 1.11.2018.

Nagar, S.K., Malukar, O., Kubavat, D., Prajapati, V., Ganatra, D. \& Rathwa, A. (2012) Students' 
perception on anatomy teaching methodologies. National Journal of Medical Research, 2, 1, pp. 111-112.

Jaiswal, R., Sathe, S., Gajbhiye, V. \& Sathe, R. (2015) Students perception on methods of anatomy teaching and assessment. International Journal of Anatomy and Research, 3, 2, pp. 11031108.

Fischer, R.L., Jacobs, S.L. \& Herbert, W.N. (2004) Small Group Discussion versus Lecture Format for Third Year Students In Obstretic And Gynecology. Obstetrics and Gynecology, 104, 2, pp. 349-353.

McKeown, P.P., Heylings, D.J., Stevenson, M., McKelvey, K.J., Nixon, J.R. \& McCluskey D.R. (2003) The impact of curricular change on medical students' knowledge of anatomy. Medical Education, 37, pp. 954-961.

Prince, K.J., Scherpbier, A.J., van Mameren, H., Drukker, J. \& van der Vleuten, C.P. (2005) Do students have sufficient knowledge of clinical anatomy? Medical Education, 39, pp. 326-332.

Heylings, D.J.A. (2002) Anatomy 1999-2000: the curriculum who teaches it and how. Medical Education, 36, pp. 702-710.

Older, J. (2004) Anatomy: a must for teaching the next generation. Surgeon, 2, PP. 79-90.

Sritharan, K. (2005) The rise and fall of anatomy. British Medical Journal, 330, pp. s255.

Bandyopadhyay, R.\& Biswas, R (2017) Students' Perception and Attitude on Methods of Anatomy Teaching in a Medical College of West Bengal, India. Journal of Clinical and Diagnostic Research, 11, 9, pp. AC10-AC14.

Samar, A., Abdulhadi A., Ayuob, S., Bassem, E. \& Amira, E. (2010) A model of horizontal and vertical integration of teaching on the cadaveric heart. Annals of anatomy, 192, pp. 373-377.

Dunnington, G., Witzake, D., Rubeck, R., Beck, A., Mohr, J.\& Putnam, C.A. (1987) Comparison of the teaching effectiveness of the didactic lecture and the problem oriented small group session: a prospective study. Surgery, 102, 2, PP. 291-296.

Rokade, S.A. \& Bahetee, B.H. (2013) Shall we teach anatomy with chalk and board or power point presentation? An analysis of Indian students' perspective and performance. Scholars Journal of Applied Medical Sciences, 1, 6, pp. 827-842.

Kumari, R., Yadav, A.K., Singh, B., Kaur, M. \& Gupta, R. (2015) Evaluating anatomy teaching methodology as per the perception of first MBBS students- A questionnaire based study. International Journal of Basic and Applied Medical Sciences, 5, 2, pp. 240-244

Petimani, M.S. \& Adake, P. (2015) Blackboard versus power point presentation: students opinion in medical education. International Journal of Educational and Psychological Researches, 1, pp. 289-292

Chakrabarti, S., Shilpkala, L.B. \& Raghunath, G. (2017) Teaching and learning perception of anatomy by first MBBS (2014-15) batch students. Indian Journal of Clinical Anatomy and Physiology, 4, 1, pp. 87-91.

Bamne, S.N. \& Bamne, A.S. (2016) Comparative study of chalk board teaching over power point teaching as a teaching tool in undergraduate medical teaching. International Journal of Medical Science and Public Health, 5, 2, pp. 2585-2587.

lan, C. (2012) Formative assessment assessment is for self-regulated learning. Educational Psychological Review, 24, 2, pp. 205-249.

Chakrabarti, S., Vijayalakshmi, S. \& Raghunath, G. (2017) Problems and difficulties encountered by first year MBBS students in learning medical anatomy and some of its solutions- a feedback study. International Journal of Pharma and Bio Sciences, 8, 4, pp. 40-48. 